\title{
El Delito y la Sanción Penal
}

\author{
Por el doctor Julio Altmann Smythe (1)
}

\section{LA NOCION DEL DELITO}

Los fenómenos criminógenos se han presentado desde los albores de la Humanidad y continúan manifestándose en nuestros días. Con razón se afirma que la historia del delito se confunde con la del hombre. Es lógico, por tanto, de que el ser humano haya tenido siempre alguna concepción de lo que es el delito, aunque en una forma bastante imprecisa.

La noción que se ha tenido del delito ha ido cambiando paralelamente con las modificaciones que han experimentado costumbres e ideas. Como el hombre ha evolucionado incesantemente, sus opiniones, es natural, igualmente se han ido transformando. Viviendo el ser humano, por otro lado, en un mundo que sufre contínuos cambios, es comprensible que sus concepciones hayan variado constantemente. La idea que se ha tenido del delito, pues, ha mudado de acuerdo a las épocas y las regiones en que el ser humano desarrollaba sus actividades.

Lo que cyer se consideró como un acto perjudicial para el individuo y para el conglomerado social, actualmente suele conceptuarse en forma distinta. La mente humana se admira de muchas concepciones que acerca del delito prevalecieron en la antigüedad.

Muchos actos que en el pasado se estimaron como graves crimenes, se les tiene hoy como no delictuosos. Asímismo, acciones u omisiones conceptuadas en otras épocas como normales y hasta necesarias, en la actualidad se les tiene como serios delitos. Por ejemplo, en otros tiempos se consideraba muy grave crimen el pensar en materia religiosa en forma diferente a lo estatuído por el Estado o por la mayoría de los habitantes, por lo que se penaba con la muerte generalmente toda herejía. Hoy, felizmente, se considera esta libertad de conciencia como un derecho de todo individuo. Por otro lado, era frecuente entre los pueblos primitivos dor muerte a sus ancianos y a los niños mal conformados o débiles, lo que se conceptuaba conveniente para el grupo social. Igualmente, no constituía delito el matar al propio esclavo. Aun en períodos más recientes, el marido ultrajado tenía pleno derecho para matar impunemente a su esposa y al aman. te, al sorprenderlos en infraganti delito de adulterio. Ahora se piensa en

(1) Ex-Catedrático de Derecho Penal en la Univeroidad Nacional Mayar de San Marcas; ex-Director General de Establecimientos Penolos $\mathrm{I}$ de Tutela $\mathrm{y}$ alto tuncionaxio de las Naciones Unidas. En los Nos. XXII Y XXIII de oata Rievista, homos publicado otras interescanles colaboraciones del Doctor J. Altmann Smythe. 
forma diferente.

Lo señalado no significa que actualmente no existan pueblos, de escasa evolución mental, que sigan pensando como en esas distantes épocas. Continúan sintiendo y pensando en la misma forma que sus remotos antepasados. No han desaparecido, pues, muchas ideas del pasado en algunos pueblos y personas. Aún en las agrupaciones humanas supuestamente evolucionadas no faltan hombres $y$ mujeres que poseen una deformada concepción de lo que es delito, seguramente porque se encuentran imbuídos por ideas ya superadas. Algunas de estas personas juzgan como legítimos muchos actos que la conciencia colectiva y la misma Ley conceptúan como delictuosos.

La concepción del delito igualmente ha variado caprichosamente, dependiendo de los intereses que al sector dominante convenía defonder. $\bar{A} 1$ no existir normas precisas que determinaran qué actos eran o no delictuosos, la noción del delito era cambiante, generalmente de acuerdo a la omnímoda voluntad de los jueces, que hacían prevalecer una extremada arbitrariedad, según los intereses que estaban en juego o las personas que los habian cometido. No debe admirar que en esos tiempos no se conociera con antelación qué actos eran considerados delitos e, igualmente, qué penas podrían aplicarse en cada caso. La opresión ejercida por los sectores privilegiados, o por el Estado, sobre los individuos se manifestaba frecuentemente calificóndose como crímenes a muchos actos inocuos, si así convenía a la clase gobernante. Por tanto, la idea de lo que podría considerarse como delito no era posible fijarse en esos tiempos, relativamente cercanos.

Actualmente, en la mayoría de las naciones civilizadas el hombre conoce anteladamente qué actos serán conceptuados como delictuosos, habiendo disminuído los señalados excesos por la aplicación recta de la Ley penal. Con el advenimiento del salvador principio "nullum crimen, nula poena sine lege" se ha consagrado una nueva situación más justa. La Ley. buena o mala, ha dado al ser humano un conocido "status" jurídico, el que teóricamente debe ser respetado. Por otro lado, el hombre ha logrado tener una noción más clara de lo que es el delito.

Sin embargo, la concepción del delito se ha visto influída por una Sociedad que cambia de contínuo, lo que ha dado lugar a la aparición de nuevas modalidades delictivas. Paralelamente $\alpha$. la evolución social, económica, cultural, etc. del conglomerado social y del hombre mismo, la concepción del delito ha ido variando, por cuanto los mismos fenómenos criminólogos van cambiando de fisonomía. Pero cabe concluir de que la idea que se teng̣a del delito dependerá, en último término, de los valores individuales y sociales juzgados como importantes $\mathrm{y}$, por ende, dignos de recibir una efectiva protección penal. La noción, pues, es 'siempre inconstante.

Generalmente se estima como delictuoso el acto humano que daña - atenta contra los bienes espirituales o materiales del individuo o de la Sociedad. Se trata, incuestionablemente, de una noción simple y muy amplia. Muchos de estos actos legalmente no constituyen un delito en forma invariable, ya que la estimación del acto delictuoso constituye una opera: ción mental muy compleja. Por lo menos, nunca es sencilla. Ālgunos ejemplos aclararán lo dicho. 
Hoy radie duda de que el valor que preferentemente debe ser protegido es la vida humana. Sin embargo isiempre constituye un acto delictuoso el matar a un semejante? A veces, no se tipifica como delito esta acción, toda vez que no basta el destruir una vida humana para que el autor se convierta en asesino. Por ejemplo, no comete delito el verdugo que ajusticia al condenado a la pena capital, ni el que mata en legítima defensa. Tampoco es un delincuente el soldado que quita la vida al enemigo en un acto de guerra. Aunque en todos estos casos se ha producido la muerte de un semejante, la Ley no los considera como delictuosos. Siempre deben estimarse las peculiaridades del acto $\mathrm{y}$, naturalmente, lo que determina la Ley.

Pero cualquiera que sea la inconstante concepción que se tenga del delito, siempre se trata de una conducta reprensible y punible, ttpificada por la Ley penal como delictuosa y sancionable. No interesa que esta conducta sea condenada o aceptada por la conciencia colectiva, la que cambia sin cesar. Empero "el Derecho Penal no es la ley a secas", como bien lo afirma Luis Jiménez de Assúa, quien agrega: "El Derecho Penal abarca las vivencias del pueblo en que rige. Hay un derecho supralegal, al que a menudo tenemos que acudir para establecer los conceptos positivos $y$ negativos de la antijuridicidad".

Cabe concluir que - como lo afirma Eugenio Cuello Calón- "es inútil buscar una noción del delito en si", por cuanto la concepción del delito se desvanece o se hace sumamente vaga debido a los múltiples factores que la modifican sin interrrupción. Todo intento para dar una noción del delito, independiente de los tiempos y lugares, ha resultado absolutamente estéril, ya que el crimen, siempre presente, va tomando diferentes características a la evolución de la propia Humanidad.

\section{LA DEFENICION DEI DELITO}

Los antiguos Códigos penales definían el delito indicando que "es la acción u omisión voluntaria penada por la ley". La mayoría de los Códigos modernos no dan definición del delito. Quizás tengan razón para hacerlo así, toda vez que, en el fondo, toda definición de delito importa un silogismo, cuya conclusión repite un mismo concepto con distintas palabras. En verdad, estas definiciones plantean el problema, sin resolverlo. Nada agregan a lo que se ha dejado expresado en el anterior capítulo de este estudio. Es por estos motivos que; al igual que los códigos, muchos tratadistạs modernos huyan de dar definiciones de delito.

Algunos tratadistas han intentado definir el delito. Pero todos éllos repiten idénticos conceptos, con pequeñas variaciones, como puede constatarse en las siguientes:

Rossi, por ejemplo, indica que el delito "es la infracción de un deber requerible, en daño de la sociedad o de los individuos".

Filangieri señala que "es un hecho humano contrario a la ley".

Carrara dice que "el delito es la infracción de la ley del Estado pro. mulgada para seguridad de los ciudadanos, resultante de un acto externo del hombre, positivo o negativo, moralmente imputable y políticamente dañoso". 
Para Adolfo Franck "es la violación de un derecho".

Garófalo lo define, diciendo "el delito social o natural es una lesión de aquella parte del sentido moral que consiste en los pensamientos altruistas fundamentales (piedad y probidad) según la medida con que se encuen. tran en las razas humanas superiores, cuya medida es necescria para la adaptación del individuo a la sociedad".

Grispigni juzga que el delito es "la conducta humana correspondiente al tipo descrito por una norma penal, que no presenta causas de justificación y que, además, es psíquicamente referible a un sujeto".

Von Belíng define el delito diciendo. 'Es una acción, típica, antijuridica, culpable, cubierta por una sanción penal adecuada a la culpabilidad y que llena las condiciones legales de punibilidad".

Jiménez de Âsúa dice: "Es delito la acción u omisión culpable, típicamente antijurídica (es decir, no comprendida en las causas de justificación), penada por la ley, imputable a un sujeto responsable (esto es, que no se halle incluido en una de las causas de imputabilidad) y sometida, en ciertos casos, $\alpha$ una condición externa de punibilidad (como en el supuesto de la quiebra culpable o fraudulenta, que exige previa declaración de ésta"). $O$ en esta forma, más sintética "es el acto típicamente antijurídico, culpable, sometido $\alpha$ veces a condiciones objetivas de penalidad, imputable a un hombre y sometido a una sanción penal".

López-Rey lo enuncia en forma bastante sencilla. "Delito es un acto típicamente antijurídico, imputable $\alpha$ un hombre y sometido a una sanción penal".

José Ingenieros construye una definición sociológica: El Delito es "una trasgresión de las instituciones impuestas por la sociedad al individuo en la lucha por la existencia. Lesiona directa o indirectamente el ajeno derecho a la vida, cuyas condiciones son establecidas por la ética social y tienden a fijarse en fórmulas jurídicas, variables según las circunstancias de tiempo, modo y lugar". Se trata, sin duda, de una definición bastante amplia y correcta.

Thorsten Sellin lo define: "Generalmente se admite que la criminalidad es el hecho de una conducta o de acciones prohibidas por la ley y que exponen al delincuente a penas limitativas de su libertad, privativas de su vida o que le imponen obligaciones que, en razón de su carácter restrictivo, no le son agradables".

Otros autores definen el delito como una acción $\mathbf{u}$ omisión prohibida por la ley, bajo la amenaza de una pena. Otros, con brevedad, señalan que delito es "Iq violación de la ley que lo sanciona".

Ocioso sería continuar dando a conocer otras definiciones de delito.

Como es de verse, aunque expresados en términos distintos, todos abundan en concepto idénticos, como ya se ha dicho.

No existe, por otro lado, una permanente definición del delito de tipo filosófico. Como piensa Manuel López-Rey: "toda definición de delito tiene un valor histórico $\mathrm{y}$ es problable que más adelante, al evolucionar la Cultura y cor élla el delito haya que dar una definición diferente". Cabría preguntarse, entoncés ¿una definición de delito, correcta hoy, lo será en un distante futuro? 


\section{LA LUCHA CONTRA EL CONTROL}

Invariablemente el hombre ha reaccionado enérgicamente frente a todo acto conceptuado como perjudicial para el individuo o para los vitales intereses del grupo social al que pertenecía. Esta reacción ha variado sin cesar en sus formas $Y$ en sus fines. Por otro lado, igualmente las concepciones que se ha tenido de lo perjudicial ha cambiado de contínuo.

Pero durante siglos y siglos más que hablarse de una lucha contra el crimen, debería referirse $\alpha$ una lucha contra el criminal, al que se intentaba destruir 0 , en el mejor de los casos, castigar. Quizás si en forma inconciente se ha procurado combatir el delito en sí mismo, pero es indudable que los medios usados para lograrse este fin han sido predominantemente aquéllos que buscaban la sanción del delincuente. Sólo en los últimos tiempos la lucha contra el crimen se halla orientada a la rehabilitación del criminal, para que no reincida, o a otorgar a todos los individuos de un ambiente que impida o frene la tendencia de llegar hasta el delito.

La reacción primitiva que buscaba la destrucción del criminal ha persistido durante siglos $\mathrm{y}$, seguramente, hasta en la misma época actual, tendencia que no sólo se halla reflejada en las actitudes humanas, sino en los textos de las mismas leyes punitivas. Lo que significa que la reacción primigenia sigue perdurando en la actualidad, por más que doctrinariamen. te se desee lo contrario. Persisten, pues, muchas fórmulas poco evolucionadas en la actualidad, sin que se pueda adivinar cuándo podrán ser eliminadas totalmente. Sin embargo, a medida que el hombre se ha ido perfeccionando, estas reacciones se han morigerado. Finalmente, es digno de señalarse que estas reacciones, que en un comienzo fueron especialmente do carácter individual y familiar, hoy tienden a hacerse predominantemente sociales.

En esta lucha, la sociedad ha empleado medios muy diferentes para - defenderse del delito y del delincuente. Prácticamente, desde la pre-historia hasta hace relativamente poco, el medio empleado era el castigo, cruel e inhumano. Se ha pensado que con sanciones rigurosas se intimidaria a los potencialmente criminales, evitándose que llegaran hasta el delito. Tam'bién se ha creído que si el delincuente expiaba su crimen sufriendo un se. vero castigo, no reincidiaría. La experiencia y las estadísticas disponibles comprueban que tales medios han fracasado en los intentos de la sociedad de vencer al delito. Posteriormente advino el llamado sistema correccional, que, como su nombre lo indica, buscó la corrección del criminal modiante la aplicación de diversas medidas, en el fondo todas éllas sancionadoras, con los resultados absolutamente negativos que se conocen. En la actualidad se pretende rehabilitar individual y socialmente al individuo que ha cometido un delito o que presenta tendencia a llegar hasta el crimen, usán. dose métodos más humanos y científicos, los que, hasta el momento, igualmente han tracasado. Cabe concluir que, en la lucha contra el crimen, nunca se han alcanzado efectos positivos, cualquiera que hayan sido log sistemas aplicados. Es incuestionable que la sanción penal constituye un arma inapropiada para vencer al delito.

La sanción penal constituye, sin duda, un reproche social, imprescindible frente al acto delictivo y a su autor. Pero también es un sufrimiento 
que se impone al delincuente, siguiéndose la tendencia vengativa de otros: tiempos. No hay duda que con estos criterios de venganza nunca podrá derotarse al fenómeno delictivo. La más simple lógica permite afirmar que el ser humano no limitará sus impulsos delictivos a base del peligro que. significa un hipotético padecimiento.

Es sabido, por otra parte, que en las prisiones actuales abundan los inocentes $y$ que en éstas no se encuentran recluidos todos los que merecen: esta sanción penal. Las autoridades policiales y los magistrados judiciales muchas veces fallan en sus actividades y llegan a equivocaciones muy serias. Si esto es así, no debe extrañar que todo delincuente crea que su delito ha de permanecer impune $\mathrm{y}$ que las autoridades jamás podrán inculparlo. Algunos autores sostienen que la mayoría de los delincuentes no llegarían hasta el delito si supiesen, con certeza absoluta, que no quedarían impunes, suponiendo que el temor al castigo frenaría sus impulsos delictivos. Es verdad que, como afirma Marco Antonio Dupont Muñoz, "La conciente 0 inconciente aspiración a la impunidad está presente en todo ciudadano". Entre éstos, es natural, que deba comprenderse a aquéllos que tienden a la criminalidad. Pero, no obstante esta aspiración a la impunidad, la antisociabilidad se presenta debido a múltiples factores físicos, psíquicos y sociales, en los que influyen mínimamente las ideas de impunidad o de: castigo.

Debe, empero, convenirse que, durante los últimos decenios, en el terreno teorético especialmente, reflejado pálidamente en el campo práctico, se han realizado muchos y muy meritorios esfuerzos en busca de una prevención general $y$ especial del delito, que tenga efectividad en la lucha contra el crimen.- Si bien es verdad que se constata una benéfica evolu. ción en las orientaciones prevalecientes, sus resultados, hasta ahora, han sido tan negativos como antes.

Algunos tratadistas juzgan que este fracaso se debe a que se han aplicado desacertadamente los métodos humanos y científicos propugna. dos por la tnoderna Ciencia Penológica. Es incuestionable que estos autares tienen alguna razón para hacer esta afirmación, ya que los viejos métodos permanecen, en su esencia, intactos, no obstante las innovaciones que se afirma han sido introducidas. En el mejor de los casos, se ha logrado un producto híbrido, el que, como es obvio, no puede ser fecundo. Aunque en teoría se ha marchado hacia adelante y se han hecho progresos efectivos, desde el punto de vista de la práctica se ha continuado recorriendo los habituales caminos, como lo señala Sergio Jacomella, quien concluyó afirmando que "perseverar en viejas concepciones, sistemas anticuados Y prejuicios arcaicos significaría tomar una actitud retrógrada, irracional e ilógica". Es por tales razones que la mayoría de los autores afirman que si se sigue intentando combatir el crimen a base de la aplicación de sanciones en forma predominante, en esta perenne lucha siempre saldrá vencedor el delito, debiéndose, por tanto, abandonarse estos métodos, que requieren ser superados. Mientras se trate de perseverar en el empleo de métodos anticuados, tan empíricos como los usados en épocas primigenias, la criminalidad no podrá ser derrotada, sino que, más bien, se verá fortalecida, como hasta ahora, haciéndose cada vez más frecuente y peligrosa.

Pero, es sabido, las actividades humanas dependen específicamenté 
de tres factores básicos: $\alpha$ ). - Las condiciones individuales; b). - Las condiciones del medio ambiente; $y$ c).- Otros factores influyentes en los anteriores, de diferente naturaleza, cuyos efectos pueden ser positivos o negativos. Por eso es dable pensar que si las reacciones frente al delito y al delincuente buscaran el robustecimiento de aquéllos que poseen una acción. positiva sobre las demás, sería de esperar que la criminalidad disminuyera sustancialmente.

La Humanidad ansía vencer al fenómeno delictual y busca desesperadamente alguna o algunas fórmulas que la lleven a realizar tal anhelo. Sin pecar de optimistas, es dable pensar que se logre, si no un remedio efectivo para las actividades delictuosas, cuando menos un inteligente lenitivo, siempre que la reacción estatal frente al crimen y a los criminales se humanice y se haga más científica, aceptándose las constructivas doctrinas contemporáneas.

Claro está que la tarea no será sencilla; seguramente se convertirá en una acción sumamente difícil. Pero lo esencial es encontrar los nuevos métodos y aplicarlos con persistencia, si se desea alcanzar algún éxito en la lucha contra el delito. Como lo ha indicado Saporito, ante todo será sustancial "en determinar ese punto de apoyo que buscaba Árquímedes para poder levantar al mundo".

Algunos tratadistas sostienen que esta lucha contra el delito habrá de continuar en el futuro, no importa los nuevos métodos que se apliquen para eliminar al crimen. Juzgan que jamás faltarán valores 0 intereses que el grupo social estime importantes $y$ dignos de ser defendidos penalmente, así como sujetos que los amaguen o ataquen, en una u otra forma. Finalmente, opinan que, mientras la Humanidad vaya adoptando más eficaces fórmulas prra combatir el crimen, éste irá tomando, por su parte, nuevas fisonomías $y$, en especial, adquirirá distintas resistencias, por lo que es muy hipotético que el delito sea vencido totalmente alguna vez y en forma definitiva. Como lo dice el Profesor Manuel López-Rey: "La Historia acredita una constante evolución del delito y no su desaparición".

\section{LAS SANCIONES PENALES}

Denominados simplemente "sanciones" por algunos tratadistas, aI considerar que las de carácter "penal" son las únicas que deben tener este denominativo.

La norma jurídica determina que algunos actos humanos dan lugar a una coacción, impuesta por el Estado, aplicable al autor de una conducta ilícita. Al acto coactivo se le llama "sanción". Consiguientemente, se la puede definir diciendo que es el acto coactivo, dispuesto $y$ ejecutado por específicos organismos del Estado, dirigido contra el autor de una conducta señalade por la norma legal como condicionante de tal apremio.

La mayoría de los autores distinguen dos clases de sanciones: las civiles y las penales. Las primeras tienen el objetivo básico de ordenar una reparación por el hecho antijurídico. Las segundas, además de imponer esta reparación, aplica al autor del acto una medida suplementaria, contemplada en la ley, aspirando $\alpha$ que el acto antijurídico no se repita. Debido $\alpha$ : la índole de este trabajo, sólo nos ocuparemos de las sanciones penales. 
La Sanción Penal es siempre la consecuencia jurídica específica del Delito y constituye el medio con el que el cuerpo social, representado por el Estado, pretende defenderse de los fenómenos delictivos.

Las sanciones penales son de dos tipos: a). - Las Penas; y b). - Las medidas de Seguridad. Sin embargo, Manuel López-Rey distingue tres tipos: 1). - Las penas; 2). - Las medidas de seguridad; $\mathrm{y}$ 3). - Las medidas penales. Esta clasificación es propia del distinguido penalista, quien ha creado un tercer tipo denominado "medidas penales", que se refieren $\alpha$ las sanciones aplicables a las personas jurídicas. Seguiremos la primera división, que es la más aceptada.

Algunos autores juzgan que entre la pena y las medidas de seguridad no existen diferencias cualitativas $y$, por tanto, es erróneo hacer tal distinción. Es indudable, empero, que existen desemejanzas entre dichas sanciones penales, aunque, en la práctica, desaparezcon a veces.

En su importante estudio "La Regulación Jurídica de la Ejecución Pe nal", el Profesor argentino Mario I. Chichizola indica las diferencias siguientes, entre las más saltantes:

"a). - La pena se impone teniendo en cuenta la gravedad del delito cometido, mientras que la medida de seguridad se aplica en atención a la peligrosidad del delincuente, revelada por sus condiciones personales, más que por el hecho perpetrado".

"b). - Se aplica la pena a los individuos que son imputables penalmente: en cambio la medida de seguridad rige generalmente para los sujetos que son penalmente inimputables".

"c). - La pena importa un sufrimiento y una amenaza, mientras que la medida de seguridad no tiene por objeto causar un sufrimiento, ni tampoco es una amenaza, pues se aplica $\alpha$ individuos incapaces de sentir la "coacción psicológica que la pena implica". Y

"d). - La duración de la pena es determinada de acuerdo al hecho punible. Por el contrario, la medida de seguridad es indeterminada; se prolonga mientras no cese la peligrosidad del individuo".

Aunque no estamos de absoluto acuerdo con la opinión del Prof. Chitchizola, debemos convenir que, en general, deben aceptarse diferencias importantes, aunque sea en sus formas, entre estas sanciones penales.

Es común que la mayoría de las personas sólo consideren las "penas" entre las sanciones penales, generalmente desconociendo las "medidas de seguridad". Como afirma López-Rey, es necesario puntualizar que "el término sanción es más amplio que el de pena y comprende a ésta y a las medidas de seguridad". Sin embargo, como lo señala Filippo Grispigni, poseen ambas caracteres comunes, toda vez que dos son aplicadas por los mismos órganos jurisdiccionales, con iguales procedimientos y garantías y atienden a la defensa del Estado frente al fenómeno delictivo. Aún más en algunos casos, las medidas de seguridad suelen sustituir a la pena.

Cabe terminar indicando que no es posible confundir las medidas de seguridad con las "medidas preventivas". Las medidas de seguridad siempre son impuestas después de la comisión de un delito, mientras que las 
medidas preventivas actúan antes de la ejecución del acto delictuoso, previniéndolo y obrando sobre los individuos que denotan claramente una peligrosidad social.

\section{LA PENA}

Existen innumerables definiciones de la pena. Sölo se uurớn a conocer algunas pocas.

Carrara considera que la pena es un mal que, de conformidad con la ley del Estado, los magistrados infligen a aquellos que son reconocidos como culpables de un delito.

Según Pessina, es un sufrimiento que recae, por obra de la sociedad humana, sobre aquél que ha sido declarado cutor de un delito, como único medio de reafirmar el derecho.

Florión sostiene que la pena es el tratamiento que el Estado impone, con fines de defensa social, al que haya cometido un delito y aparezca como socialmente peligroso.

Para Impallomeni la pena es "la pérdida o disminución de bienes jurídicos personales, impuesta por el Estado, a los autores de un delito, en conformidad con sus leyes".

Listz juzga que la pena es "el mal que el juez impone al delincuente, a causa del delito, para expresar la reprobación social con respecto al "acto y al outor".

Cuello Calón la define diciendo que "la pena es el sufrimiento impuesto por el Estado, en ejecución de una sentencia, al culpable de una infracción penal".

Mezger opina que la pena es una retribución, esto es, la imposición de un mal adecuado al acto delictuoso, consistente en una privación de bienes juŕdicos, que recce sobre el autor del delito.

Sellin estima que las penas son privaciones, limitaciones u obligaciones que, por su carácter restrictivo, no son agradables, impuestas por el Eftado al autor del delito, conforme a la ley.

Sebastián Soler la define señalando que " es un mal, amenaza primero y luego impuesto al violador de un precepto legal, como retribución, consistente en la disminución de un bien jurídico y cuyo fin es evitar los delitos".

Para Mario I. Chichizola "la pena es la retribución, consistente en la privación o restricción de bienes jurídicamente protegidos, que impone el Estado por intermedio de sus órganos jurisdiccionales competentes al cutor de un delito".

Otros indican que la pena es una privación o restricción de bienes jurídicos que pertenecen al delincuente (vida, libertad, propiedad, honor, etc.), siempre impuesta por el Estado, para conservar el orden jurídico o para restablecerlo, cuando ha sido perturbado por un delito, (prevención $Y$ represión), realizado por los tribunales de justicia, después de un juicio penal, medida que debe consistir en aquella que la ley establece y dentro de los límites fijados por la misma.

Como es de verse, la mayoría de las definiciones estiman que la pena es un mal, un sufrimiento, que actúa primero como una amenaza y, después, como una imposición, sufrida por el violador de un precepto legal 
que así lo establece. Es una retribución al delito. Para Kant la pena es un imperativo categórico, lógica y específica consecuencía del delito. Algunos conceptúan que la pena es un tratamiento impuesto al delicuente, el que no debe tener carácter aflictivo, ya que éste puede comprometer sus fines rehabilitadores y curativos. Otros estiman que la pena no es un mal-como Roeder, Pedro Dorado Montero. Concepción de Arenal, etc. - sino un bien para el autor del delito, ya que tiende a reformarlo.

El eminente penalista español Jaime Masaveu afirma que "la pena no sólo envuelve un designio moral de ejemplaridad, "castigo", sino, especialmente, un propósito social de "defensa". Su filosofía es utilitaria, no dogmática". Consecuentemente, cree que la primera razón de ser de la pena no es la justicia - con ser la pena por esencia acto jurídico-antes bien, de necesidad. Señala que la defensa social necesita de la pena, para que pueda efectuarse. Es difícil de aceptar este pensamiento de Masaveu, ya que la pena ha demostrado ser arma absolutamente inócua para verificar una efectiva defensa social contra el crimen, por lo menos tal cual se la aplica actualmente.

Las opiniones difieren profundamente, ya que se asigna dístintas finalidades a la pena. Mientras algunos ven en élla una reacción social defensiva, otros la consideran como un medio de reforma y rehabilitación del delincuente. No faltan, aún, aquéllos que la tienen como una mera ven. ganza, convertido el instinto de Ia "defensa-ofensa" de Ferri, propia del hombre primigenio, en una actitud social, razonada. Pero, es necesario convenir, que por más que en nuestra época se haya intentado restarle todo carácter aflictivo, la pena continúa siendo una imposición de obligaciones dolorosas, esto es, un padecimiento. Persiste en la pena una tendencia rencorosa, un espíritu de represalia. Si bien es verdad que la pena se ha humanizado debido a diversas influencias sociales, culturales, etc., jurídicamente considerada la pena continúa siendo un mal, un sufrimiento $y$ una retribución al acto delíctuoso. Su carácter expiatorio no ha desaparecido, por más que se trate de rehusarlo.

Sin embargo, algunos autores niegan que la pena persiga, como en pretéritas épocas, una venganza o una expiración, ni tampoco una retribución del mal con el mal, ni siquiera una tranquilidad o seguridad. Juzgan que sus finalidades son muy distintas, ya que la pena procura la readaptación del delincuente $y$, al mismo tiempo, la intimidación general, dirigida a to. dos, y una especial, respecto al propio. criminal. Opinan, finalmente, que con la pena se trata de convertir a una persona perjudicial en otra que no lo sea. Empero, aceptan que hay delincuentes que no necesitan de la pena y otros para los cuales es absolutamente inútil, ya que para los últimos no hay readaptación posible.

No hay duda de que el concepto de "pena" ha ido variando a través de los siglos. Al disminuirse una extrema crueldad, se la ha humanizado un tanto. Pero no ha perdido sus antiguas características. Por tanto, sigue tan inútil como siempre para cumplir con una efectiva defensa social. Mediante la pena no se logra ni logrará la prevención general $y$, mucho menos, la especial.

Consecuencia lógica de lo dicho es que deban ser renovados los ya anticuados fundamentos y métodos del sistema penal. Como afirma López- 
Rey: "Hay que crear una nueva concepción que se preste a una mejor defensa de la sociedad contra el crimen".

Al quitarse a la pena su extrema rigidez, haciéndosela más flexible, y al permitirse cierto arbitrio judicial, entre un máximo y un mínimo, para que el Magistrado pueda graduar la pena de acuerdo a las circunstancias diversas que rodean al delito y a la propia personalidad del delincuente, es indudable que se ha avanzado algo. Refuerza este avance el intento de individualizar la pena, lo que se ha logrado gracias a la Escuela Positiva, que proclamó la necesidad de adecuar la pena a las características personales del criminal. Pero, en el fondo, estas conquistas pertenecen al terreno teórico, reflejado pálidamente en el práctico. Por ejemplo, tal sucede con la individualización de la pena, la que puede ser, como se sabe, legal, ju. dicial y ejecutiva o administrativa. La primera dista de hacerse factible, $y^{\alpha}$ que es muy general y sólo dispone el establecimiento de límites máximos y mínimos a la duración de la pena, considerándose circunstancias agravantes $y$ atenuantes. La judicial presupone, o debe presuponer, el científico conocimiento del delincuente por los magistrados. Pero, es sabido, los jueces igncran generalmente la verdadera personalidad del culpable, $y a$ que no cuentan con los medios imprescindibles para éllo. Y la ejecutiva, debido a que la pena ya se halla dictada, sólo puede realizar una individualizaciór. relativa de la pena ya impuesta, siempre y cuando el personal administrativo conozca científicamente al condenado, lo que es muy raro.

La comisión de un delito siempre ha merecido una general repulsa, una persistente persecución y una pena, variable de acuerdo al acto delictuoso mismo, a las circunstancias que lo han rodeado, a las cacarterísticas objetivas del delincuente, etc. Debe irse a nuevas medidas, que no sólo signifiquen un rechazo social, sino que, en verdad, persigan la efectiva readaptación socio-jurídica del criminal. Al mismo tiempo, el propio Derecho Penal debe dejar de ser, como hasta ahora, un mero formulismo jurídico. Al delincuente hay que considerarlo siempre no como un ente abstracto, sino como un ser humano, con sus flaquezas, sus tendencias, sus anomalías, etc., a fin de encontrar las medidas técnicas que permitan su readaptación social. Las enseñanzas del Papa Pío XII deben, igualmente, contemplarse, cuando afirmaba que era necesario colocar al centro del sistees que las penas actuales no podrán regenerar al delincuente, especialmente como son aplicados.

Con hondura, Saporito señaló: "No existe hombre que bajo el efecto persistente de una acción regeneradora, ferviente $y$ racional, no pueda más o menos ser reformado de manera de responder a las exigencias de la sociedad civilizada." Pero ¿cuál será esa acción regeneradora?. Lo cierto es que las penas actuales no podrán regenerar al delincuente, especialmente como son aplicadas.

Existen, indudablemente, variadas y contrapuestas opiniones acerca de la finalidad y efectividad de la pena. Sería ocioso sopesar estos pareceres, porque cualquier conclusión a la que se llegue fundadamente podría ser tachada de parcial. Sin embargo, la experiencia de siglos ha enseñado que la pena es ineficaz para combatir el delito, toda vez que éste es producto de múltiples factores (antropológicos, físicos, psíquicos, sociales, etc.. etc.) y con la aplicación de esta sanción no se logrará limitarlo $y$, mucho 
menos, eliminarlo.

Debe reconocerse, sí, que la supervivencia universal de la pena constituye un elocuente indicio de que la sociedad continúa considerándola útil. Ha resistido a la evolución de conceptos, costumbres, etc., ha vencido, pues, al mismo progreso, lo que quiere significar, al menos, que la Humanidad ha sido incapaz, hasta el presente, de hallar un mejor sustituto. De esta suerte, por tanto, la pena continúa siendo la consecuencia natural del delito, que es su obligado antecedente.

\section{IAS MEDIDAS DE SEGURIDAD}

En general, estas medidas tienen la finalidad de procurar que el delincuente no reincida, ya obteniendo su readaptación social o bien segregando a los incorregibles.

Algunos atisbos de esta sanción penal se hallan en la Roma Imperial y sus antecedentes inmediatos se encuentran en la teoría de los sustitutos penales de Ferri y en las medidas preventivas de Lombroso. Pero su verdadero creador fué Von Liszt.

Como ya se ha expresado, no deben confundirse las "medidas de seguridad" con las actualmente denominadas "medidas preventivas", sustancialmente diferentes.

Tampoco deben confundirse con la pena, aunque ambas constituyen sanciones penales. Empero, tanto las unas como la otra responden, hasta ahora, a la teoría de la retribución, aunque no se desee aceptar tal opinión. Como lo afirma Von Liszt, no hay una verdadera oposición entre ambos conceptos, toda vez que las medidas de seguridad poseen, en esencia, las características de la pena las más de las veces y se hallan, al igual que la pena, unida íntimamente a la comisión de un delito, antecedente de ambas sanciones. Por otro lado, casi todas las medidas de seguridad poseen un fondo penal, toda vez que entre ciertos internamientos asegurativos y las penas de prisión prácticamente no existen diferencias sustanciales. Aún más. La mayoría de las medidas de seguridad, al igual que la pena, im. portan un sufrimiento, no obstante la pretención de algunos autores en negarlo.

Es bien sabido que la enorme mayoría de los especialistas sienten una enorme desconfianza en la eficacia de la pena. A este respecto dice León Rabinowics, aunque parcializado, al defender conceptos positivistas: "La introducción de las medidas de seguridad en los códigos penales prueba que la pena, tal cual es concebida por las escuelas clásica y ecléctica. es incapaz de asegurar la defensa de la sociedad contra el delito; prueba la necesidad de sustituir el postulado de la retribución y de la expiación -base de la construcción penal clásica- por el principio de la defensa social y de reeducación -base de la construcción penal positiva". Debido al pabre concepto que se tiene en los efectos de lạ aplicación de la pena, se piensa que podrían lograrse mejores resultados si se la complementa con las medidas de seguridad. Esta es la razón de que exista una fuerte tendencia en los códigos penales modemos de complementar sus sistemas de penas con un extenso sistema de medidas de seguridad, $\alpha$ las cuales, erónea o acertadamente, se les ha dado una importancia excepcional, 
tanto que algunos tratadistas creen que el presente siglo será considerado como el siglo de las medidas de seguridad, en vista de la enorme trascendencia que se les ha otorgado. No faltan aquéllos que indican que no es exagerado decir que estas medidas constituyen el punto central, no sólo do la ciencia penal, sino también del derecho positivo.

En verdad, tal como se las viene aplicando, presentan muchos caracteres comunes con la pena, al extremo que el distinguido penalista colombiano Luis Carlos Pérez afirma que entre la pena y las medidas de. seguridad se ha tratado, bastante inútilmente, de crear diferencias. Sin. embargo, no faltan tratadistas - como Stoos y Langhi- que hallan muy. sustanciales disimilitudes entre ambas sanciones penales.

Von Liszt define a las medidas de seguridad diciendo que son "todos los medios por los cuales se trata de obtener la adaptación del individuo a la sociedad (medidas educadoras y correccionales) o la eliminación de los inadaptables a la sociedad (medida de protección o de seguridad, en su riguroso sentido).

Para Zurcher "son las reglas que el juez impone cuando ha comprobado la culpabilidad de un acusado responsable, tanto accesoriamente a la pena, como en lugar de ésta, con el objeto de prevenir nuevos delitos".

Según Cuello Calón son "ciertas medidas impuestas por el Estado. a determinar los delincuentes, encaminados a obtener su adaptación a la vida social (medida de educación, de corrección o de curación) o su segregación de la misma ( medidas de seguridad, en su sentido estricto).

Impropiamente, algunos sostienen que estas medidas, en sus formas educativas, son de aplicación a los menores. Se sabe que las medidas de seguridad se imponen a los delincuentes. Hallándose el menor fuera del codigo punitivo, jamás comete delito como el adulto, no es juzgado y nunca. puede considerársele un delincuente. Consiguientemente, no puede ser objeto de sanción penal alguna. Los menores poseen su propia jurisdicción y propio Código, respondiendo a los nuevos conceptos hoy predominantes.

Se imponen medidas de seguridad de carácter curativo, educativo $\mathbf{Y}$ correctivo a los delincuentes adaptables socialmente. Así, a los delincuen. tes anormales mentales, alienados, toxicómanos, alcohólicos, etc. se les interna en establecimientos especiales para ser tratados y lograr su posible curación; a los mendigos y vagabundos habituales que hayan cometido infracción penal se les interna $a$ fin de que se adapten a una vida de trabajo: algunos individuos delincuentes semi-civilizados son internados para que puedan adquirir la evolución mental y de hábitos que es característica de las sociedades superiores, etc.. etc.

Las medidas segregativas se imponen a los delincuentes habituales que sean oparentemente incorregibles, las que consisten en el intermamiento de estos sujetos, con tines de seguridad.

Es de indudable interés comprobar que muchas de las medidas de. seguridad importan privación de libertad: internamiento de alcohólicos, toxicómanos, alienados, anormales mentales, mendigos, vagos habituales, etc., pero otras son francamente privativas de la libertad del individuo, como las que se aplican $\alpha$ los delincuentes estimados inadaptables. Estas medidas difieren en muy poco con la pena de privación de libertad.

Hay medidas que no privan de libertad al delincuente: prohibición. 
de ejercer ciertas profesiones, expulsión de los extranjeros, mandato a no rconcurrir a determinados lugares, etc. Estas medidas generalmente se aplican concurrentemente con la pena, para ser cumplidas una vez cumplida ésta.

Como bien lo señala Cuello Calón, a los individuos peligrosos no delincuentes (alienados peligrosos, ebrios, toxicómanos, rufianes, etc.) se les aplican medidas preventivas, en ocasiones impuestas por las mismas autoridades judiciales $y$ conforme a las reglas procesales, medidas que no deben confundirse con las medidas de seguridad. Por lo general, las medidas preventivas, tal cual el nombre lo indica, se aplican para prevenir el delito, esto es, las reciben los sujetos peligrosos que aún no han llegado al crimen. Las medidas de seguridad, ya se ha dicho, se aplican a los delincuentes, generalmente dispuestos por el Código Penal. Este cuerpo de leyes normalmente no dispone las medidas preventivas, las que se hallan contenidas en cuerpos legales autónomos, los que suelen llevar distintas denominaciones: "Ley sobre el Estado Peligroso sin Delito", "Ley de Vagos Y Maleantes", etc., etc.

\section{LA INEFICACIA DE IAS SANCIONES PENALES}

En anterior capítulo se ha dado a saber la opinión de los tratadistas acerca de la infructuosidad que ha tenido la aplicación de las sanciones pe. nales. Pero algunos autores sostienen que estos negativos efectos se deben, particularmente, a que estas sanciones se han venido aplicando hasta aho. ra erróneamente, afirmando que lo malo no se halla en las sanciones penales mismas, sino en la manera como vienen funcionando $y$ en los desviados tines que se le confieren. Finalmente, señalan que la existencia legal de estas sanciones, dado el escaso progreso alcanzado en el campo de la Penología, se encuentra justificada y que mientras no sea factible reem. plazarlas por otras medidas más eficaces, no será posible desterrarlas por completo. Pero, insisten, en que se impone se las aplique con criterios diferentes a los que prevalecen hoy.

No cabe duda de que la mayoría de las medidas de seguridad no difieren, en el fondo, de las penas, por lo que sería ilógico cifrar muchas esperanzas en sus efectos. Sin embargo, cuando la medida significa tratamiento educativo y curativo, aplicado a determinados delincuentes, es in. cuestionable que responden las medidas de seguridad a una visión cien. tífica, pudiéndose esperar resultados promisorios. Pero en lo que se refiere a la pena, la que continúa constituyendo un sufrimiento y una retribución, hay que convenir que difícilmente podrá producir la readaptación social e individual de los delincuentes; salvo casos aislados, los que seguramente habrían alcanzado su rehabilitación aún sin que sufrieran sanción penal alguna. No obstante su relativa humanización y pretendida individualización, la pena ha resultado siempre un fracaso.

Predomina actualmente la tendencia de restar a la pena su crueldad, juzgándose que una pena más humanizada es la de privación de la libertad, la que ha adquirido, al presente, casi absoluto predominio, tanto que su aplicación legal se ha vuelto indiscriminada y hasta abusiva. Todo el sistema represivo de hoy gira al rededor de esta pena.

Constituyendo la pena privativa de la libertad el eje del sistema penal, es natural que se la estudie con alguna amplitud. 


\section{IA PENA PRIVATIVA DE IA IJBERTAD}

Ia finalidad de esta pena es recluir al delincuente en un estableci. miento y sumeterlo $\alpha$ un tratamiento, científico e individualizado, dirante un período pre-establecido, buscando la rehabilitación individual $y$ social del sujeto.

El éxito del tratamiento siempre es inseguro, pero, lo peor es que, al condenarse al culpable a reclusión por un tiempo determinado, no se contempla que el tratamiento requerirá un mayor período que el que tija la sentencia condenatoria o menor. En un caso, este tratamiento quedará trunco y en el otro será excesivo. Por tal motivo, es lógico que la pena privativa de la libertad debiera tener un carácter de indeterminación en lo que se refiere al período en que el delincuente deba estar recluído. Su duración no debe, consiguientemente, señalarse a priori, sino fijarse, según los resultados obtenidos por el tratamiento, durante la fase posterior a la sentencia.

Es cierto que el actual sistema constifuye una garantía para el delincuente contra las arbitrariedades de las autoridades. Pero es ilógico, por cuanto es imposible fijar por adelantado el tiempo que ha de demorar el tratamiento al que se somete al penado, para que se alcance su rehabilitación. Ya en 1868, Próspero Despine, combatiendo este sistema, escribió: "Ia duración del tratamiento no puede sèr limitado de antemano".

"El período de encarcelamiento deberá invertirse en asegurar, en la medida de lo posible, que al reincorporarse el delincuente a la sociedad no sólo tenga el deseo de hacer una vida digna, de trabajo y de. respeto a la ley, sino que, además, esté en condiciones de llevar a cabo sus propósitos", señala el Informe del Primer Congreso de las Naciones Unidas sobre Prevención del Delito y Tratamiento del Delincuente, celebrado en Ginebra, en 1955. Este es, sin duda, el objetivo que se le ha asignado a la pena de prisión. Pero jes inteligente el privar $\alpha$ un individuo de su libertad cuando se pretende prepararlo para la vida en libertad? ¿Será factible para el penado adquirir las necesarias aptitudes para hacer una convenjente vida social, si se le impone una existencia antinatural de aislamiento social? ¿En un ambiente artificial distinto absolutamente al que ha de regresar cuando egrese de la prisión, será posible alcanzar la rehabilitación del perado? ¿De qué manera podrá alcanzarse este propósito si se sumerge al recluso en un ambiente mucho peor al que tenía anteriormente?

Una persona no se transforma radicalmente, de la noche a la mañana, en un ser diferente a sus congéneres por el sólo hecho de haber cometi. do un delito. Pero en la prisión se le trata como si así lo fuera, en un ambiønte no usual. Fatalmente, debido a este hecho, adquiriró una mente anornalizada, ya que, como lo señala Molinario, distinguido penalista argentino, cualquiera que sea la forma en que las prisiones estén organiza. das, o por mucho que traten de asemejarse a una sociedad normal, el hecho msimo de estar en prisión, que siempre supone cierto automatismo y simplificación de vida, trae inevitablemente ciertas consecuencias deplorables. 
La pena privativa de la libertad no sólo significa para el culpable. su reclusión en un establecimiento penal, sino, especialmente, un casi total aislamiento social, retraimiento que no se halla únicamente representado por muros y rejas, sino, en particular, por el sistema de vida al que se le somete, siempre artificial y antinatural. Como lo ha dicho G. Kempe: "Es innegable que las prisiones, por bien organizadas que estén, represen. tan una colectividad de carácter coercitivo, con ambientes absolutamente antinaturales". En verdad, por más que se intente aplicar los principios más técnicos, no existe una prisión que posea un ambiente que permita al recluso llevar una existencia racional, ya que todas ellas constituyen la antítesis de una regular comunidad libre.

Es sabido que el penado fué un sujeto responsable de sus actos, buenos o malos; que tomaba, con una relativa libertad, sus propias decisiones: que poseía sentimientos de auto-respeto; que gozaba de la amistad de muchas honestas personas; que cuidaba de sí mismo y de su familia; que era, y sigue siéndolo, un hijo, un esposo y un padre; etc. Pero el establecimiento penal lo separa de sus familiares y amigos, alejándolo de su medio habitual, para obligarlo a convivir con sujetos socialmente peligrosos: lo impide tomar sus propias e independientes decisiones, constreñido por reglamentaciones que deben ser obedecidas irrefragablemente; le impone múltiples limitaciones y una vida irregular, disminuyéndolo en su calidad, de ser humano; etc. Esto es, le otorga un modo de ser que da al recluso una mente estereotipada, haciéndolo perder la costumbre de convivir con otras personas que llevan una existencia regular y restándole el poder de conocer el valor de las cosas que ha de ofrecerle la sociedad, al egresar de la prisión.

Por más esfuerzos que se hagan para lograr la rehabilitación sociojurídica del penado, será sumamente difícil que se alcance este ideal en un ambiente tan artificial. Más bien, al salir de la prisión, se hallará peor equipado que cuando ingresó a élla para hacer frente a una vida social en libertad. Se ha olvidado un certero pensamiento de Joly: "El momento en que el culpable entra en la cárcel es un momento crítico para él; pero. el momento en que sale de la misma es un momento crítico para él y para nosotros". Es entonces que el ex-penado deberá enfrentar $\alpha$ una sociedad para él olvidada $Y$, por tanto, desconocida y los múltiples prejuicios hondamente arraigados en los grupos sociales, que hará que lá comunidad lo trate con desconfianza $y$, a veces, con franca hostilidad.

\section{EL FRACASO DE LA PRISION}

Es indudable que la prisión ha fracasado como institución de defensa de la sociedad contra el delito. Sus nulos resultados han persistido a través de siglos, no obstante las mejoras técnicas que se le han introducido en los últimos tiempos. Las cifras de las reincidencias certifican oue la pena privativa de la libertad y la prisión no conducen a la prevención especial $y$, por ende, hasta ahora han significado rotundos fracasos.

Una de las más prestigiosas autoridades penitenciarias norteamerica: nas, Sanford Bates, en su interesante obra " ¿Han fallado nuestras prisiones?", refiriéndose a los establecimientos penales de su país, afirma: "Es 
ineficaz y anticuado nuestro actual sistema penitenciario. No reforma al criminal, no protege a la sociedad". Lo indicado por Bates puede referirse a las prisiones de todos los países, sin excepción. Un juicio muy acertado es el de Thorsten Ericksson, eminente especialista sueco: "En el terreno del tratamiento de los delincuentes todas las naciones están subdescrrolladas. Incluso países que por circunstancias fortuitas pueden considerarse como bien desarrollados, económica y socialmente, han de reconocer que la forma de tratar la delincuencia dista mucho del grado de desarrollo general alcanzado en los demás órdenes".

Inspiradas en las Reglas Mínimas para el Tratamiento de los Reclusos, elaboradas por las Naciones Unidas, algunas naciones han expedido disposiciones carcelarias bastante perfeccionadas. Pero una cosa es legislar y otra, aplicar estos preceptos. En la mayoría de estos países se compruebo una completa ausencia de paralelismo entre la norma y su aplicación práctica, lo que, es indudable, conduce a una situación falsa e inconveniente. El Dr. Manuel López-Rey ha visitado en los cinco continentes cerca de setenta países, estudiando sus instituciones penitenciarias. Ha constatado en sus viajes que no más del seis o siete por ciento mantenían cierta correspondencia entre sus disposiciones legales y las prácticas carcelarias y que en ninguno se aplicaban, en su totalidad, las Reglas Mínimas para el Tratamiento de los Reclusos de esta Organización Mundial. Llega a la conclusión de que es sumamente perjudicial esta contradicción y este desequilibrio entre la ley y los servicios penintenciarios existentes.

Las cárceles, a fuerza de pretender cumplir con una función de defensa social, se han convertido en entidades agresoras de una bien organizada sociedad. Los mejores especialistas convienen en que la prisión de hoy no tiene ningún efecto beneficioso $y$ que, más bien, acentúa la hostilidad social de los penados. El hecho cierto es que la pena privativa de la libertad no ha producido los resultados que se esperaban de su aplicación. Aunque se enfocara el serio problema carcelario con criterios netamente conservadores, pero honestos, habria que admitir que los establecimientos penales, en el mejor de los casos, no sirven sino para aislar a los penados de la comunidad, posiblemente protegiendo a ésta de determinados peligros durante algunos años y cumpliendo para el delincuente una limitada función de castigo, de intimidación, de disciplina, de control, de vigilancia y de seguridad. En verdad, no sirven para nada más, tal cual ahora marchan.

Jiménez de Asúa ha escrito: "La prisión de hoy sigue siendo escuela del crimen, más que casa de enmienda. Hay que ir necesariamente a una transformación completa del sistema vigente y acaso a una sustitución de éste por otros medios mejores". Y sus ideas van mucho más lejos, cúando dice: "La cárcel, que lleva como consecuencia inevitable anomalías a la psique del reo, es la más absurda de todas las penas, ya que la disposición anímic'a a lo ilegal, a lo antisocial, se agudiza por las condiciones anormales y contrarias a la vida humana del régimen de las prisiones. Se han hecho esfuerzos para remediar este enorme fracaso de la cárcel. Se han inventado reformatorios, sistemas de trabajo, regímenes penitenciarios, se han acortado las penas, pero como el mal radica en el aislamiento, los esfuerzos no han tenido logro, salvo en contados casos". La natural conclu- 
sión a la que habrá de llegar es que la prisión continuará siendo un tracaso, por más reformas superficiales que se le introduzcan, por cuanto el fracaso proviene de la córcel misma.

Hay que aceptar, sin embargo, que dados los actuales adelantos de la Penología, será prócticamente imposible desterrar plenamente los sistemas penitenciarios. En el Primer Congreso Panamericano de Medicina Legal, Odontología Legal y Criminología, celebrado en La Habana, Cuba, en 1947, el ilustre outor del Código de Defensa Social cubano. José Agustín Martínez, decía: "El fracaso de la cárcel ya no se discute. Claro está que pueden obtenerse córceles mejores, es decir, que sirvan mejor al fin que la sociedad se propuso al establecerlas; pero, en general, su descrédito es grande y universal. Cunado se medita sobre ello y se conocen sus resultados, llegamos a la conclusión de que lo mejor que podría hacerse con las cớrceles es suprimirlas todas". Pero el mismo penalista agrega: "Sólo hay un inconveniente para que esta determinación sea un desiterátum: ¿con qué sustituiremos las cárceles? Ni aún los más encarnizados enemigos de la cárcel llegarían a esta conclusión radical. La cárcel, aunque constituye un recurso detestable, es, hasta ahora, irreemplazable". El juicio del doctor Martínez es perfectamente razonable. No cabe sino continuar aceptando el funcionamiento de estos negativos sistemas penales, aunque intentando, siempre, mejorarlos básicamente. En especial, hay que darles un tono más natural, justamente para procurar a los reclusos, dentro de lo factible, una existencia normal. Como lo señaló J. W. Braithwaite, Director de un establecimiento penal de Canadá: "Ya es hora de experimentar en las prisiones la revolución social que ocurrió en el campo de la higiene mental. La administración de los manicomios ya no teme el procurar a los enfermos mentales una existencia parecida a la que lleva el individuo normal en su comunidad, porque ya no oye los falsos argumentos con relación a sus hospitrles que desgraciadamente se continúan empleando al referirse a las instituciones penitenciarias".

Si la pena privativa de la libertad ha fracasado en su aplicación, es imprescindible ir a su paulatina desaparición, ya que no es aceptable eliminarla radicalmente. Es conveniente recordar que esta pena no es sino uno de los múltiples recursos que puedan emplearse para controlar la delincuencia y que la Penología ha creado nuevas medidas mucho más útiles y efectivas, de las cuales hay que hacer un uso más constante.

De acuerdo a la opinión de los más respetados tratadistas, no es posible, por ahora, desterrar completamente la pena privativa de la libertad. Pero sí se impone la humanización y la tecnificación de las prisiones. Quizás si habría que reactualizar el pensamiento de Oscar Wilde: "No son los reclusos a los que hay que reformar; sino a las cárceles". El primer paso que hay que dar para terminar con la inapropiada fisonomía de la prisión actual es la ruptura de las barreras, hasta ahora infranqueables, que sepa. ran, en forma tajante, a los penados de las personas que aún no han delinquido o que, por lo menos, no se conocen sus actos delictuosos. Esta valla mental es la causa principal de que los establecimientos penales respondan a requerimientos diferentes de las personas que viven en una comunidad regular, haciéndose olvido de que el delincuente, como todos los in. dividuos, es un producto de una sociedad normal $\mathrm{y}$, también, un miembro 
de ella. Si es verdad que con su actuación ha causado un perjuicio a la sociedad, de donde proviene, $y$ que el actual penado ha llegado hasta el delito llevado por múltiples circunstancias, muchas de las cuales se han producido por culpa de la misma sociedad, no constituye el mero perjuicio ocasionado mérito bastante para tratarlo como un ser sui géneris, como un ser aparte, diferente en todo $\alpha$ los demás integrantes del conglomerado social.

Conforme a esta opinión, son muchos los penitenciaristas que anhelan destruir esta artificial barrera. No lo han logrado aún, pero la valla va cediendo poco a poco. Es de esperar que al fin alcancen sus nobles propósitos, consideróndose que las presentes condiciones del mundo son propicias para franquear muchos límites que separan a los hombres, casi siempre barreras que no responden a razón alguna. Por lo menos, con la prisión abierta se han acercado a este ideal, significando este tipo de establecimiento uno de los más serios intentos para romper esta barrera, asemejando la vida de los reclusos a la que se lleva en una comunidad libre. Aunque con la prisión abierta no se va a dor solución integral al problema planteado, por lo menos se haró mucho para que desaparezca la artificialidad del antiguo tipo de prisión.

\section{HACIA LA SUSTITUCION DE LA SANCION-CASTIGO}

En vista del fracaso de las sanciones penales que se imponen actualmente a los delincuentes, sería lógico e inteligente que éstas fueran paulatinamente sustituídas por otras medidas más apropiadas, que puedan conducir, dentro de lo posible, a la verdadera rehabilitación individual $y$ social de los infractores. Hay que partir del principio de que, fuere cual fuere la causa del delito, ésta no ha de desaparecer espontáneamente. Mucho menos procurando al criminal ambientes antinaturales, como son los que existen en los establecimientos penales, los que, no obstante todos los esfuerzos que se han hecho para mejorarlos, continúan siendo especies de reliquias de una mentalidad de pretéritas épocas. Porque si subsisten los factores personales, sociales, etc. que llevaron al sujeto hasta el crimen o si se les agrava colocándose al delincuente en un sitio tan irregular como es la cárcel, no cabe pensar que el criminal podrá rehabilitarse, como se desea. En verdad, como lo ha dicho Ruiz-Funes: "Si nos obstinamos en seguir adheridos a los viejos criterios penales, podemos afirmar con lógica que la lucha contra la criminalidad devendrá en un espectáculo grotesco".

Es sabido que el sujeto que llega hasta el crimen lo hace impulsado por múltiples factores, los que conjugan entre sí para producir la explosión infraccional. Estos factores pueden ser predominantemente personales, sociales, etc, los que deben ser conocidos después de técnicos estudios. En seguida hay que ayudar a su neutralización, brindando al sujeto un medio social propicio, una curación científica, una reeducación verdadera, etc. Es la únicá forma de evitar que estos factores nuevamente empujen al individuo al sendero de la antisociabilidad. Estos resultados sólo excepcionalmente podrán alcanzarse con los actuales sistemas punitivos. Se impone, por tanto, transformar la sanción-castigo de hoy en una sanción-clínica, la que funcionaría fundándose en similares conceptos a los que hoy se emplean con los enfermos mentales. 
Sin embargo, estos fundamentales cambios encuentran seria oposición en la pertinaz actitud de la mayoría de los especialistas jurídico-penales, los que, no obstante que el moderno sistema de penas y medidas de seguridad ha demostrado su ineficacia, continúan situando en él el centro de gravedad de la acción que debe tomarse frente al delito y al delincuente. Esta oposición de los penalistas especialmente se debe a que poseen un miraje del problema completamente limitado y unilaterizado, por lo general. Sus ideas rara vez se hallan revitalizadas con los conocimien. tos de la Ciencia Penitenciaria y de la Criminología, disciplinas que tienen una indiscutible importancia y que gozan de una clara autonomía. Quizás si este hecho venga a explicar que la mayoría de los penalistas con tinúen apegados a un sistema inapropiado, con una insistencia negativa. Como es natural, esta posición fatalmente se refleja en el contenido de los códigos penales.

Como lo ha dicho Manuel López-Rey: "No es posible, en nuestra épo$c a$, mantener lo penal exclusivamente afirmado en principios, ideas, ideologías y métodos que se encontraban ya vigentes en el siglo XVIII. Vivimos ahora otra vida y necesitamos también y paralelamente, como aspecto importante de una nueva orientación jurídica, un Derecho Penal más en consonancia con los nuevos conceptos y exigencias". Pero, no obstante que la experiencia y los datos estadísticos aseguran que la sanción-castigo ha fracasado siempre, se continúa defendiéndola. Hay que recordarles que la defensa social no se alcanza a base de meros "principios generales", sino con "resultados".. Y que estos resultados únicamente podrán lograrse aplicando medidas más efectivas que la sanción-castigo, esto es, con medidas expresamente destinadas a corregir, reeducar, ambientar y curar a los delicuentes, tal cual nos dictan las leyes históricas y los datos que nos proporcionan los hechos y la misma evolución social de la Humanidad.

¿Con qué medidas podrá sustituirse la sanción-castigo para que se obtengan mejores resultados?. Naturalmente, no es fácil hacer una afirmación inequívoca, toda vez que estas medidas no han funcionado aún en la práctica $\mathrm{Y}$, por ende, sus resultados han de ser hipotéticos mientras no se las aplique. Por otro lado, aunque en el fondo están de acuerdo, existen diferencias en las opiniones de los partidarios de esta sustitución.

Marco Antonio Dupont Muñoz dice, al respecto: "Tengo la seguridad de que el camino por seguir es el de la terapia analítica de grupo... Para ello es requisito lógico la evalución de la doctrina penitenciaria". Hernett se muestra partidario de que la pena sea sustituída por la terapéutica y que los presidios se transformen en clínicas sociales. La Comisión Internacional y Penitenciaría, mediante Resolución del 6 de Julio de 1951, recomienda las "medidas de defensa social" o medidas de protección", las que se aseme. jan mucho a lo que teóricamente debieran ser las medidas de seguridad. Para Saldaña, estas medidas tienen un carácter totalmente diferente a las diversas sanciones penales de la actualidad, toda vez que las primeras son racionales $\mathrm{v}$ técnicas.

Refiriéndose el mismo Saldaña a estas medidas escribe: "El régimen futuro se anuncia como una realización extra penal. En él los delitos no deberán hublar al instinto, sino a la razón; y, como antes pedían al sen- 
timiento de venganza una pena, ahora se alzan esos crímenes mostrando a la concienca social una medida salvadora. De la acción impulsiva, que es aquella, a la acción reflexiva, que ha de ser ésta, corre todo el proceso de la cultura jurídico-penal".

Hastci ahora, la conversión de la sanción-castigo en la sanción-clínica constituye un simple ideal. Hay que convenir que los conceptos expuestos no podrán llegar a ser realidad de inmediato, sino en un distante futuro seguramente. Sin embargo, debe tenerse presente que si la Humanidad ha evolucionado hacia realidades mejores es porque han habido ideales, los que que han ido mostrando el camino, como la estrella de Belén. Y como lo ha dicho ese gran argentino que se llamó José Ingenieros: " $E_{n}$ el vaivén eterno de las eras, el porvenir es siempre de los visionarios". 